Tropical Journal of Pharmaceutical Research May 2021; 20 (5): 1073-1078

ISSN: $1596-5996$ (print); 1596-9827 (electronic)

(C) Pharmacotherapy Group, Faculty of Pharmacy, University of Benin, Benin City, 300001 Nigeria.

Available online at http://www.tjpr.org

Original Research Article

http://dx.doi.org/10.4314/tjpr.v20i5.27

\title{
Studies on the pharmacokinetics of piperacillin/ tazobactam in renal replacement therapy in patients with chronic renal failure
}

\author{
Qinqin Ma*, Hongyuan Xiao, Yannan Zhang, Chen Chen, Ying Zhou, Yunning \\ Liu, Tianmin Li, Yinghua Yu \\ The First Affiliated Hospital of Hebei North University, Intensive Care Unit, Hebei 075000, China
}

*For correspondence: Email: shoulibenci3270@163.com

Sent for review: 7 December 2020

Revised accepted: 28 April 2021

\begin{abstract}
Purpose: To study the pharmacokinetics of piperacillin/tazobactam in renal replacement therapy (CRRT) in patients with chronic renal failure (CRF).

Methods: Six CRF patients treated with CRRT in the First Affiliated Hospital of Hebei North University from April 2020 to July 2020 were selected and administered $4 \mathrm{~g}$ of piperacillin and $0.5 \mathrm{~g}$ of tazobactam within 30 min after, and at 5, 30, 45, 60, 90, 120, 180, 240, 360 and 480 min after CRRT. The DAS software was used to calculate pharmacokinetic parameters while linear regression was used to analyze the relationship among patient characteristics, CRRT parameters, and pharmacokinetics.

Results: The $C_{\max }$ of piperacillin and tazobactam was 118.46 (96.12 - 161.12) $\mathrm{mg} / \mathrm{L}$ and 27.45 (14.75 28.45) $\mathrm{mg} / \mathrm{L}$, while the volume of distribution $\left(V_{d}\right)$ was $1.16(0.72-1.59) \mathrm{L} / \mathrm{h}$ and $0.72(0.57-0.82) \mathrm{L} / \mathrm{kg}$, respectively. The value for elimination half-life ( $\left.t_{1 / 2}\right)$ was $4.66(3.19-8.45) h$ and $4.25(3.42-5.96) h$, while total clearance (CL) was 7.28 (5.58 - 9.73) L/h and 6.37 (4.28 - 10.04) L/h, respectively. Multivariate linear regression showed that piperacillin $C_{\max }$ was negatively correlated with the flow velocity of the substitution fluid $(\beta=-0.679,95 \% \mathrm{Cl}=-0.278-0.943, p<0.001)$. Piperacillin $C L$ was positively correlated with the flow velocity of the waste liquid $(\beta=0.956,95 \% \mathrm{Cl}=1.267-4.796, p<$ 0.001).

Conclusion: When used in CRF patients receiving CRRT, piperacillin and tazobactam show decrease in $C_{\max }$ and $C L$, but increase in $t_{1 / 2}$. This finding should provide useful guidance for clinicians concerned.
\end{abstract}

Keywords: Piperacillin/tazobactam, Chronic renal failure, Renal replacement therapy, Pharmacokinetics

This is an Open Access article that uses a fund-ing model which does not charge readers or their institutions for access and distributed under the terms of the Creative Commons Attribution License (http://creativecommons.org/licenses/by/4.0) and the Budapest Open Access Initiative (http://www.budapestopenaccessinitiative.org/read), which permit unrestricted use, distribution, and reproduction in any medium, provided the original work is properly credited.

Tropical Journal of Pharmaceutical Research is indexed by Science Citation Index (SciSearch), Scopus, International Pharmaceutical Abstract, Chemical Abstracts, Embase, Index Copernicus, EBSCO, African Index Medicus, JournalSeek, Journal Citation Reports/Science Edition, Directory of Open Access Journals (DOAJ), African Journal Online, Bioline International, Open-J-Gate and Pharmacy Abstracts

\section{INTRODUCTION}

Chronic renal failure, the terminal stage of chronic kidney disease, presents with obvious renal atrophy, and impairment of body functions such as excretion, acid-base balance and body fluid maintenance. It is characterized by high incidence, severe complications, and poor prognosis $[1,2]$. The major objective of clinical treatment is to delay worsening of the disease and improve prognosis. Renal failure leads to hemodynamic instability. Continuous renal replacement therapy (CRRT) is a favorable treatment option for renal failure patients [3]. 
However, while CRRT removes body fluids and solutes, it also clears drugs from the body, resulting in an impact on the pharmacokinetics (PK)/pharmacodynamics (PD) of drugs. Piperacillin and tazobactam are drugs frequently used in the treatment of chronic renal failure. This study analyzed the pharmacokinetic characteristics of piperacillin and tazobactam in patients with chronic renal failure receiving CRRT, and investigated the associated influencing factors, with a view to providing a guide for clinical administration of these drugs.

\section{METHODS}

\section{General information on patients}

This is a prospective study. This study was approved by the Ethical Committee of the First Affiliated Hospital of Hebei North University (approved no. 2018KY283). This study was performed in accordance with principles of the Declaration of Helsinki [4]. All patients signed informed consent. Patients with chronic renal failure who received CRRT treatment in our hospital from April 2020 to July 2020 were included. The included patients were: (1) patients with complete clinical data, aged 18 to 70 years; (2) patients who met the diagnostic criteria for chronic renal failure (blood creatinine $\geq 26.5$ $\mu \mathrm{mol} / \mathrm{L}$, and glomerular filtration rate $<60$ $\mathrm{ml} / \mathrm{min}$ ); (3) patients who satisfied CRRT indications (poor diuretic response, severe electrolyte imbalance, etc.); (4) those who had not used drugs containing piperacillin and tazobactam within 2 weeks before CRRT, and (5) patients who were aware of the study objectives, and volunteered as participants. The exclusion criteria were: (1) history of infection, major trauma, and surgery within 3 months before admission; (2) use of anti-chronic renal failure drugs within 3 months before admission; (3) presence of parathyroid disease or malignant tumor; and (4) allergy to piperacillin or tazobactam. This study received approval from the ethics committee of our hospital.

\section{Renal replacement therapy (CRRT)}

The PRISMA continuous blood purification instrument and supporting pipelines and filters (area: $0.9 \mathrm{~m}^{2}$; AN69HF hollow fiber; Sweden GAMBRO Medical Equipment Company) were applied. The mode adopted was uniform continuous venous-venous hemodiafiltration for more than $12 \mathrm{~h}$. In accordance with the requirements of the guidelines, the prescribed dose of CRRT was set as the flow rate of the waste liquid $\geq 30 \mathrm{~mL} / \mathrm{kg} / \mathrm{h}$, and the doctor in charge was at liberty to increase the prescribed dose in response to changes in patient's blood pressure, acid-base balance and electrolyte disorders.

\section{Drug administration and specimen collection}

The selected patients were subjected to instillation of piperacillin $(4 \mathrm{~g})$ and tazobactam $(0.5 \mathrm{~g})$ at a uniform rate within $30 \mathrm{~min}$ after the start of CRRT, and at 15, 30, 45, 60, 90, 120, $180,240,360,480 \mathrm{~min}$ after the end of CRRT. Then, $5 \mathrm{~mL}$ of peripheral venous blood was drawn, and $2 \mathrm{~mL}$ of supernatant was taken after centrifugation and stored at $-80^{\circ} \mathrm{C}$. Based on the patient's condition, other treatments were given e.g., use of combination of other drugs, but piperacillin and tazobactam were excluded from these combinations.

\section{Chromatographic analysis}

Agilent 1260 high-performance liquid analyzer produced (Agilent Inc.) was used to measure blood drug concentrations.

\section{Chromatographic conditions for Piracillin}

The column used was Agilent ZORBAX SB-C18 (4.6 $\mathrm{mm} \times 150 \mathrm{~mm}, 5 \mu \mathrm{m}$ in diameter), and the mobile phase was $0.025 \mathrm{~mol} / \mathrm{L}$ sodium dihydrogen phosphate-acetonitrile (75:25, v:v).

\section{Chromatographic conditions for tazobactam}

The column used was Agilent ZORBAX SB-C18 (4.6 $\mathrm{mm} \times 250 \mathrm{~mm}, 5 \mu \mathrm{m}$ in diameter), with a mobile phase of $0.025 \mathrm{~mol} / \mathrm{L}$ dihydrogen phosphate sodium-acetonitrile (90: 10, v:v).

\section{Statistical analysis}

Counting data are expressed as percentage (\%), while measurement data are expressed as median or interquartile differences. The DAS software was used to calculate pharmacokinetic parameters. Spearman correlation coefficient ( $r$ ) and linear regression were employed to determine the relationship between patient characteristics and CRRT parameters and pharmacokinetic results. All statistical analyses were done with SPSS 19.0 software. Differences were deemed statistically significant at $p<0.05$.

\section{RESULTS}

\section{Patient profile}

A total of 6 patients were enrolled ( 4 males and 2 females); 66 blood samples were collected, and their drug concentrations were measured. Before 
CRRT, there were 3 cases of stage III, 2 cases of stage IV, and 1 case of stage $\mathrm{V}$ chronic renal failure. Two (2) patients received norepinephrine at a dose of $0.5 \mu \mathrm{g} / \mathrm{kg} / \mathrm{min}$ ), 3 patients received dopamine at a dose of $8 \mu \mathrm{g} / \mathrm{kg} / \mathrm{min}$ ), while 1 patient received norepinephrine and dobutamine (norepinephrine dose: $0.2 \mu \mathrm{g} / \mathrm{kg} / \mathrm{min}$; dobutamine dose: $5 \mu \mathrm{g} / \mathrm{kg} / \mathrm{min}$ ). The general information on the patients on admission is shown in Table 1.

\section{CRRT parameters of patients}

All patients used the dilution method before CRRT, and 3 patients took high-dose prescriptions due to severe acid-base imbalance (2500 mL/h for substitution fluid, $2000 \mathrm{~mL} / \mathrm{h}$ for dialysate, and total waste flow velocity of 75 $\mathrm{mL} / \mathrm{kg} / \mathrm{h}$ ). The other 3 patients were treated with unfractionated heparin for anticoagulation. The specific CRRT parameters are shown in Table 2.

\section{Pharmacokinetic parameters of piperacillin/ tazobactam}

The peak concentrations $\left(\mathrm{C}_{\max }\right)$ of piperacillin and tazobactam were 118.46 (range $=96.12$ 161.12) $\mathrm{mg} / \mathrm{L}$ and 27.45 (range = $14.75-28.45$ ) $\mathrm{mg} / \mathrm{L}$, respectively, while the values of volume of distribution $\left(\mathrm{V}_{\mathrm{d}}\right)$ were 1.16 (range $=0.72-1.59$ ) and 0.72 (range $=0.57-0.82$ ) L/kg, respectively.
Their elimination half-life $\left(\mathrm{t}_{1 / 2}\right)$ values were 4.66 (3.19 - 8.45) and 4.25 (3.42 - 5.96) h, while total clearance $(\mathrm{CL})$ values were 7.28 (range $=5.58$ 9.73) and 6.37 (range $=4.28-10.04$ ) L/h, respectively. These results are shown on Table 3. The blood concentration curves of piperacillin and tazobactam are shown in Figure 1 and Figure 2.

\section{Correlation analysis of piperacillin pharmacokinetic parameters with patient characteristics and CRRT parameters}

The correlations of pharmacokinetic parameters of piperacillin ( $\mathrm{C}_{\max }, \mathrm{AUC}, \mathrm{t}_{1 / 2}, \mathrm{CL}$ ) with patient's APACHE II score, stage, creatinine, albumin, hematocrit, substitution fluid flow velocity, dialysate flow velocity, blood flow velocity, flow velocity of waste liquid, urine output during the observation period, and liquid balance were analyzed using Spearman correlation analysis. The results showed that $\mathrm{C}_{\max }$ was correlated with substitution fluid flow velocity, dialysate flow velocity, waste fluid flow velocity, and urine volume $(p<0.001)$. Moreover, AUC was correlated with dialysate flow velocity and urine volume $(p<0.001) ; \mathrm{t}_{1 / 2}$ and waste fluid flow velocity were correlated $(p<0.001)$, while $\mathrm{CL}$ was correlated with dialysate flow velocity and waste fluid flow velocity $(p<0.001)$.

Table 1: General information on patients on admission

\begin{tabular}{lllllll}
\hline Gender & $\begin{array}{l}\text { Age } \\
\text { (years) }\end{array}$ & $\begin{array}{l}\text { APACHEII } \\
\text { (points) }\end{array}$ & $\begin{array}{l}\text { Chronic } \\
\text { renal } \\
\text { failure }\end{array}$ & $\begin{array}{l}\text { Serum } \\
\text { creatinine } \\
\text { ( } \mathbf{m m o l} / \mathbf{L})\end{array}$ & $\begin{array}{l}\text { Albumin } \\
\mathbf{( g / L )}\end{array}$ & $\begin{array}{l}\text { Hematocrit } \\
\text { value (\%) }\end{array}$ \\
\hline Male & 49 & 21 & Stage III & 495.13 & 23.56 & 17.53 \\
Male & 66 & 24 & Stage IV & 532.67 & 15.72 & 19.41 \\
Female & 65 & 26 & Stage V & 625.78 & 10.19 & 14.51 \\
Male & 29 & 19 & Stage III & 506.14 & 22.85 & 26.26 \\
Female & 61 & 20 & Stage IV & 480.35 & 19.21 & 18.13 \\
Male & 56 & 22 & Stage III & 432.29 & 23.58 & 20.52 \\
\hline
\end{tabular}

Table 2: CRRT parameter settings for patients

\begin{tabular}{lcccccc}
\hline${ }^{*}$ AC & LMWH & UFH & UFH & LMWH & UFH & LMWH \\
\hline Before administration $(\mathrm{h})$ & 1.0 & 1.5 & 1.5 & 0.5 & 1.5 & 1.0 \\
Substitution fluid flow velocity $(\mathrm{L} / \mathrm{h})$ & 2.0 & 1.5 & 2.5 & 1.5 & 2.0 & 2.0 \\
Dialysate flow velocity $(\mathrm{L} / \mathrm{h})$ & 1.0 & 1.0 & 1.5 & 1.0 & 1.0 & 1.5 \\
Blood flow velocity $(\mathrm{mL} / \mathrm{min})$ & 200 & 180 & 150 & 180 & 180 & 180 \\
waste fluid flow velocity $(\mathrm{mL} / \mathrm{kg} / \mathrm{h})$ & 75 & 69 & 63 & 74 & 71 & 66 \\
CRRT fluid balance $(\mathrm{mL})$ & 600 & 800 & -100 & 550 & 400 & 1000 \\
CRRT urine volume_(mL) & 150 & 60 & 80 & 200 & 120 & 180 \\
\hline
\end{tabular}

${ }^{*} \mathrm{AC}=$ anticoagulant; $\mathrm{LMWH}=$ high-dose prescription anticoagulant; UFH = unfractionated heparin anticoagulant

Table 3: Pharmacokinetic parameters of piperacillin and tazobactam [median (upper limit - lower limit)]

\begin{tabular}{lcc}
\hline Pharmacokinetic parameter & Piperacillin & Tazobactam \\
\hline $\mathrm{C}_{\max }(\mathrm{mg} / \mathrm{L})$ & $118.46(96.12-161.12)$ & $27.45(14.75-28.45)$ \\
$\mathrm{AUC}(0-6)\left(\mathrm{mg} \cdot \mathrm{L}^{-1} \cdot \mathrm{h}^{-1}\right)$ & $379.45(294.17-423.18)$ & $62.17(40.38-78.26)$ \\
$\mathrm{V}_{\mathrm{d}}(\mathrm{L} / \mathrm{kg})$ & $1.16(0.72-1.59)$ & $0.72(0.57-0.82)$ \\
$\mathrm{t}_{1 / 2}(\mathrm{~h})$ & $4.66(3.19-8.45)$ & $4.25(3.42-5.96)$ \\
$\mathrm{CL}(\mathrm{L} / \mathrm{h})$ & $7.28(5.58-9.73)$ & $6.37(4.28-10.04)$ \\
\hline
\end{tabular}




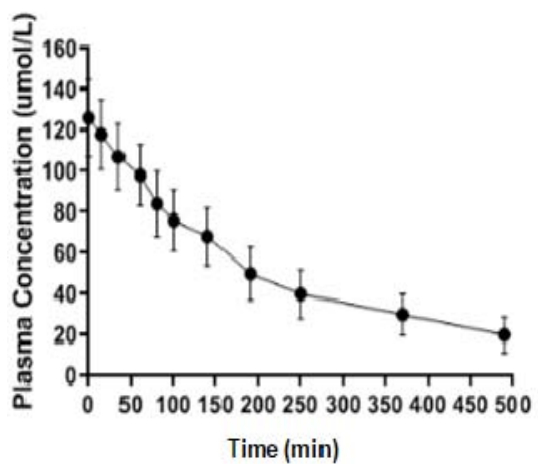

Figure 1: Changes in the plasma concentration of piperacillin over time

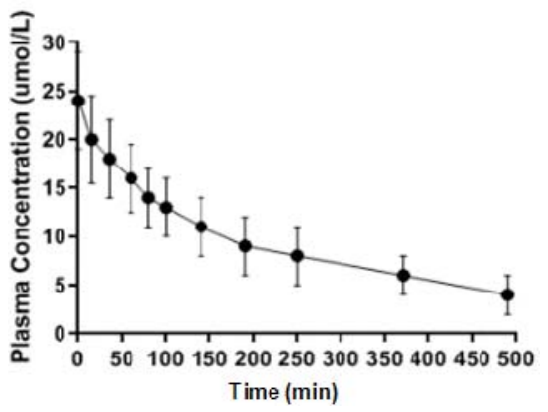

Figure 2: Changes in the plasma concentration of tazobactam with time

The pharmacokinetic results and the respective related factors were subjected to a multivariate linear regression, and the results indicated that piperacillin $\mathrm{C}_{\max }$ was significantly negatively correlated with the flow velocity of the substitution fluid $(\beta=-0.679,95 \% \mathrm{Cl}=-0.278$ $0.943, p<0.001$, Table 4). Moreover, piperacillin $\mathrm{CL}$ was significantly positively correlated with the flow velocity of waste liquid $(\beta=0.956,95 \% \mathrm{Cl}=$ $1.267-4.796, p<0.001)$. These results are shown in Table 5.

\section{DISCUSSION}

Chronic renal failure patients may experience systemic damage as time goes on until terminal stage of renal failure which requires CRRT treatment [5-10]. The disease causes a series of adverse drug reactions. It may be that CRRT removes drugs from the body when it clears body fluids and solutes, leading to poor drug effects and some adverse drug reactions [11-13]. For this reason, research on human pharmacokinetics of renal replacement therapy in patients with chronic renal failure can provide true and accurate pharmacokinetic data for evaluation of the performance of pharmaceutical preparations. Moreover, it will help to determine the necessity, research methods, and subsequent administration of large-scale clinical trials.

In this study, a prospective analysis was conducted on the first dose of piperacillin/tazobactam $(4.5 \mathrm{~g})$ in patients with chronic renal failure treated with CRRT. Under normal circumstances, the evaluation of pharmacodynamics of an antibiotic is carried out after 4 to 5 administration cycles, since the drug would have attained a stable level in the blood by that time [14]. However, for patients with chronic renal failure, it is hoped that the pharmacodynamic indicators can be reached quickly after administration, so as to delay the patient's disease deterioration early and improve prognosis. Usually, in patients receiving CRRT, drug clearance is not only affected by physiological renal clearance, but also by the external CRRT clearance.

With advances in CRRT, it is now known that many factors such as coagulation in the filter, fibrin adhesion to the filter, and polarization effect may reduce the clearance efficiency of CRRT [15]. In contrast, the clearance changes with improvement or deterioration of kidney function. Therefore, analysis of pharmacokinetics within 8 $h$ of the first dose after CRRT treatment can reduce the effects of changes in renal function and filter status on pharmacokinetics after multiple doses.

Table 4: Multivariate linear regression analysis of $\mathrm{C}_{\max }$ in the pharmacokinetic parameters of piperacillin

\begin{tabular}{lccccc}
\hline Factor & $\boldsymbol{\beta}$ & $\boldsymbol{S E}$ & $\boldsymbol{W a l d}^{2}$ & $\boldsymbol{P}$-value & OR (95\% Cl) \\
\hline $\begin{array}{l}\text { Substitution fluid } \\
\text { flow velocity }\end{array}$ & -0.679 & 0.178 & -7.629 & 0.001 & $0.507(-0.278 \sim 0.943)$ \\
\hline
\end{tabular}

Table 5: Multivariate linear regression analysis of $C L$ in the pharmacokinetic parameters of piperacillin

\begin{tabular}{lccccc}
\hline Factor & $\boldsymbol{\beta}$ & SE & Wald $\boldsymbol{X}^{2}$ & $\boldsymbol{P}$-value & OR (95\%Cl) \\
\hline $\begin{array}{l}\text { Waste fluid flow } \\
\text { velocity }\end{array}$ & 0.956 & 0.394 & 5.887 & 0.001 & $2.601(1.267 \sim 4.796)$ \\
\hline
\end{tabular}


The median plasma peak concentrations $\mathrm{C}_{\max }$ of the first doses of piperacillin $\left(\begin{array}{ll}4 & \mathrm{~g}\end{array}\right)$ and tazobactam $(0.5 \mathrm{~g})$ for patients with chronic renal failure treated with CRRT were 118.46 (96.12 161.12) $\mathrm{mg} / \mathrm{L}$ and 27.45 (14.75 - 28.45) $\mathrm{mg} / \mathrm{L}$, respectively, and they were negatively correlated with the flow velocity of the substitution fluid $(\beta=$ $-0.679,95 \% \mathrm{Cl}=-0.278-0.943, p<0.001)$. The peak plasma concentration was significantly lower than the 298 and $34 \mathrm{mg} / \mathrm{L}$ indicated in the drug insert, suggesting that CRRT affected the peak plasma concentrations of piperacillin and tazobactam $[16,17]$. The increase in volume of distribution $\left(V_{d}\right)$ may be responsible for the significant decrease in peak plasma concentration, since the increase in $V_{d}$ is common in critically ill patients. In this study, the $\mathrm{V}_{\mathrm{d}}$ values of piperacillin and tazobactam were 1.16 (0.72 - 1.59) L/kg and 0.72 (0.57 -0.82) $\mathrm{L} / \mathrm{kg}$, respectively. These values are markedly higher than those obtained earlier in a study on healthy volunteers [17].

Elevated $V_{d}$ is closely related to fluid resuscitation, hypoproteinemia and vascular endothelial injury. The elimination of piperacillin and tazobactam from the body depends mainly on the kidneys. About $68 \%$ piperacillin and $80 \%$ tazobactam are excreted through the kidneys in their original drug forms. Theoretically, glomerular filtration rate can be used as an index of the amount of drug eliminated from the body. However, there is no good method for evaluating the degree of abnormality in renal filtration in patients with chronic renal failure. Indeed, serum creatinine and urine output, which are widely used in chronic kidney disease, cannot accurately reflect renal filtration [18]. The molecular mass of piperacillin is 517.6, while that of tazobactam is 300.3 . Both are small molecules which, in theory, are easily removed through CRRT. However, in practice, the clearance rate differs with different filters, modes, and dose regimens.

The present study adopted a unified filter and mode to avoid the influence of different filters and modes on the clearance of the drugs. The usage time of the filter is controlled in a relatively narrow range $(1.0-1.5 \mathrm{~h})$ to avoid compromising the efficiency of filtration. The results of this study showed that the total clearance of piperacillin and tazobactam were 7.28 (5.58 - 9.73) and 6.37 $(4.28$ - 10.04) L/h, respectively, and they were significantly positively correlated with the dialysate flow velocity $(\beta=0.956,95 \% \mathrm{Cl}=$ $1.267-4.796, p<0.001)$. The amount of waste fluid in CRRT is the sum of total fluid volume from dialysis, replacement and dehydration, and it has been proven to be a dose indicator for
CRRT [19]. Piperacillin is a first-class elimination kinetics drug. The decrease in clearance rate and the increase in volume of distribution prolong $t_{1 / 2}$. Tazobactam serves to inhibit bacterial $\beta$ lactamase and enhance the antibacterial activity of piperacillin, and its $t_{1 / 2}$ is involved in $a$ coordinated role with that of piperacillin [20].

\section{Limitations of the study}

First, the sample size of the study is small, which may not truly reveal the pharmacokinetics of piperacillin/tazobactam during CRRT; in addition, it is a common practice to evaluate the pharmacodynamics based on the blood drug concentration. However, in patients with sepsis, the tissue (target organ) concentration of the drug may be much lower than the blood concentration, and the pharmacodynamic index calculated based on the blood concentration may overestimate the bactericidal effect.

\section{CONCLUSION}

When used in chronic renal failure patients receiving CRRT, piperacillin and tazobactam significantly decrease $C_{\max }$, increase $t_{1 / 2}$, and decrease CL. Since the cases in this study were only from one hospital, and the sample size is limited, the results may be biased. Thus, larger samples and multi-center studies are needed to enhance the reliability of the results.

\section{DECLARATIONS}

\section{Funding}

This study was supported by the Important project of Medicine and Science study in Hebei, China (Grant No.:20180825)

\section{Conflict of interest}

No conflict of interest is associated with this work.

\section{Contribution of authors}

We declare that this work was done by the authors named in this article and all liabilities pertaining to claims relating to the content of this article will be borne by the authors.

\section{Open Access}

This is an Open Access article that uses a funding model which does not charge readers or their institutions for access and distributed under the terms of the Creative Commons Attribution 
License (http://creativecommons.org/licenses/by/ 4.0) and the Budapest Open Access Initiative (http://www.budapestopenaccessinitiative.org/rea d), which permit unrestricted use, distribution, and reproduction in any medium, provided the original work is properly credited.

\section{REFERENCES}

1. Shigematsu $T$, Muraoka $R$, Sugimoto $T$, Nishizawa $Y$. Risedronate therapy in patients with mild-to-moderate chronic kidney disease with osteoporosis: post-hoc analysis of data from the risedronate phase III clinical trials. BMC Nephrol 2017; 18: 66.

2. Pinto AR, da Silva NC, Pinato L. Analyses of melatonin, cytokines, and sleep in chronic renal failure. Sleep Breath 2016; 20: 339-344.

3. Zhang L, Wang F, Wang L, Wang W, Liu B, Liu J, Chen $M, H e Q$, Liao Y, Yu X, et al. Prevalence of chronic kidney disease in China: a cross-sectional survey. Lancet 2012; 379: 815-822.

4. World Medical Association. World Medical Association Declaration of Helsinki: ethical principles for medical research involving human subjects. JAMA. 2013; 310: 2191-2194.

5. Turgutalp K, Kıykım A, Bardak S, Demir S, Karabulut Ü, Özcan T, Helvacı I, Gözükara Y. Is the red cell distribution width strong predictor for treatment response in primary glomerulonephritides? Ren Fail 2014; 36: 1083-1089.

6. Shah BV, Patel ZM. Role of low protein diet in management of different stages of chronic kidney disease - practical aspects. BMC Nephrol 2016; 17: 156.

7. Rizzetto F, Leal VO, Bastos LS, Fouque D, Mafra D. Chronic kidney disease progression: a retrospective analysis of 3-year adherence to a low protein diet. Ren Fail 2017; 39: 357-362.

8. Bellizzi V, Cupisti A, Locatelli F, Bolasco P, Brunori G, Cancarini G, Caria S, De Nicola L, Di lorio BR, Di Micco $L$, et al. Low-protein diets for chronic kidney disease patients: the Italian experience. BMC Nephrol 2016; 17: 77-77.

9. Ko GJ, Obi Y, Tortorici AR, Kalantar-Zadeh K. Dietary protein intake and chronic kidney disease. Curr Opin Clin Nutr Metab Care 2017; 20: 77-85.

10. Hekmat R, Maghsudloo F, Mohebi M, Rezaee SA, Vakili $R$, Panah HR. A study of the main determinants of sexual dysfunction in women aged 15-45 years on chronic hemodialysis. Saudi J Kidney Dis Transpl 2016; 27: 916-920.

11. Al-Biltagi M, Tolba OA, ElHafez MA, Abo-Elezz AA, El Kady EK, Hazza SM. Oxidative stress and cardiac dysfunction in children with chronic renal failure on regular hemodialysis. Pediatr Nephrol 2016; 31: 13291339.

12. Zahed NS, Ghassami M, Nikbakht H. Effects of coenzyme Q10 supplementation on C-reactive protein and homocysteine as the inflammatory markers in hemodialysis patients; a randomized clinical trial. J Nephropathol 2016; 5: 38-43.

13. Johnson DW, Atai E, Chan M, Phoon RK, Scott C, Toussaint ND, Turner GL, Usherwood T, Wiggins $\mathrm{KJ}$; KHA-CARI. KHA-CARI guideline: Early chronic kidney disease: detection, prevention and management. Nephrology 2013; 18: 340-350.

14. Kumar A, Roberts D, Wood KE, Light B, Parrillo JE, Sharma $S$, Suppes $R$, Feinstein $D$, Zanotti S, Taiberg $L$, Gurka D, Kumar A, Cheang M. Duration of hypotension before initiation of effective antimicrobial therapy is the critical determinant of survival in human septic shock. Crit Care Med 2006; 34: 1589-1596.

15. Fayad Al, Buamscha DG, Ciapponi A. Intensity of continuous renal replacement therapy for acute kidney injury. Cochrane Database Syst Rev 2016; 10: CD010613- CD010613.

16. Varghese JM, Jarrett $P$, Boots RJ, Kirkpatrick CM, Lipman J, Roberts JA. Pharmacokinetics of piperacillin and tazobactam in plasma and subcutaneous interstitial fluid in critically ill patients receiving continuous venovenous haemodiafiltration. Int J Antimicrob Agents 2014; 43(4): 343-348.

17. Bauer SR, Salem C, Connor MJ Jr, Groszek J, Taylor ME, Wei P, Tolwani AJ, Fissell WH. Pharmacokinetics and pharmacodynamics of piperacillin-tazobactam in 42 patients treated with concomitant CRRT. Clin J Am Soc Nephrol 2012; 7: 452-457.

18. Bragadottir G, Redfors B, Ricksten SE. Assessing glomerular filtration rate (GFR) in critically ill patients with acute kidney injury--true GFR versus urinary creatinine clearance and estimating equations. Crit Care 2013; 17: R108-R108.

19. Khwaja A. KDIGO clinical practice guidelines for acute kidney injury. Nephron Clin Pract 2012; 120: c179c184.

20. Liu Q, Rand K, Derendorf H. Impact of tazobactam pharmacokinetics on the antimicrobial effect of piperacillin-tazobactam combinations. Int J Antimicrob Agents 2004; 23: 494-497. 